\title{
Modelling the effect of different pricing schemes on free- floating carsharing travel demand: a test case for Zurich, Switzerland
}

\author{
${\text { Francesco } \text { Ciari }^{1} \cdot \text { Milos Balac }}^{1} \cdot$ Michael Balmer $^{2}$
}

Published online: 1 April 2015

(C) Springer Science+Business Media New York 2015

\begin{abstract}
Fundamental changes are continuing in the carsharing industry and the rapid diffusion of free-floating carsharing is one of them. The increased size of the operators and the more frequent occurrence of direct competition among them will likely make carsharing pricing a more important issue. The problem of how carsharing demand varies with different pricing strategies is the subject of this paper. An urban-scale and activity-based state-of-the-art multi-agent modelling framework was employed to evaluate alternative pricing strategies. Based on this analysis, findings suggest that pricing strategies may induce structural changes in the spatial and journey-purpose profiles of carsharing usage, and, in addition, impact aggregate demand levels and how they are distributed diurnally. The metropolitan area of Zurich, Switzerland was used as case study.
\end{abstract}

Keywords Car-sharing $\cdot$ Free-floating $\cdot$ Pricing $\cdot$ Multi-agent modelling $\cdot$ Demand modelling

\section{Introduction}

Free-floating carsharing is the most flexible form of carsharing. The system does not have stations and the members of the program can pick up and drop off the cars at any location within a predefined service area. This form of carsharing is relatively new, but is already

Francesco Ciari

ciari@ivt.baug.ethz.ch

Milos Balac

milos.balac@ivt.baug.ethz.ch

Michael Balmer

balmer@senozon.com

1 Institute for Transport Planning and Systems (IVT), ETH Zürich, Stefano-Franscini-Platz 5, 8093 Zurich, CH, Switzerland

2 Senozon AG, Schaffhauserstrasse 331, 8050 Zurich, CH, Switzerland 
present in several European and North American cities. (Shaheen and Cohen 2013) The rapid diffusion of free-floating carsharing goes together with, and in a way is shaping, fundamental changes in the carsharing industry (Briggs 2014). Simultaneously, other important changes are affecting urban travel in general. For the work presented in this paper, three observations are particularly relevant:

(1) In many cases, free-floating carsharing came to cities where a traditional, round-trip carsharing program already existed. There are cases where traditional operators extended their offer to include free-floating carsharing, but in general, new operators brought it in as competitors in the carsharing market.

(2) The two largest free-floating operators, Car2Go (Car2Go 2014) and DriveNow (DriveNow 2012), belong to important car manufacturers (Daimler and BMW, respectively). Such 'heavy-weights' entered the market with a 'big bang' approach-meaning starting operations in new cities with a large number of cars all at once-at least compared to what had been observed until then in the carsharing industry.

(3) There are more and more attempts to provide travellers with instruments, namely trip-planning apps for smart phones, that are able to thoroughly evaluate and compare all modal options available for a particular trip.

These observations have various implications. An obvious, but important implication is that in the carsharing industry both the level of competition and the size of the programs have increased substantially in a short period of time. A growing number of cities have more than one car-sharing operator active within its boundaries and there is competition amongst them. It is as yet unclear how all these players will play this game, but it seems reasonable that they will each try to capture larger shares of the market, both at the local and the global levels. Modifying prices is one way of trying to achieve this goal and operators active in highly competitive markets seem ready to go this way (Carsharing Berlin 2014). The apps mentioned above can play a role because it will be easier to systematically compare carsharing with other mobility options and the different carsharing options among them.

Pricing in carsharing did not appear to be one of the main issues for operators and has never been one of the most researched aspects of the system, but it could soon be a very popular topic. In fact, it is still uncertain how different pricing strategies could actually steer the demand for carsharing where different carsharing operators are competing. The research described in this paper moves a few steps in this rather unexplored direction. A simulation software, MATSim, which has been used in previous studies on carsharing (Ciari et al. 2012, 2013) is employed to represent a situation in which two types of carsharing are present in a delineated market (a city). The relevance of an insight into this topic is not limited to carsharing operators. The question of pricing in the carsharing market is part of the more general question of how carsharing, with more operators and larger fleets, will impact the transportation system of urban centres in the future and is therefore relevant for policy makers, planners and researchers too.

The geographic area simulated in the experiment is the metropolitan area of Zurich, Switzerland. There is already an extensive network of traditional carsharing in the area, but as yet no free-floating carsharing program. However, for the experiments, it was assumed that a free-floating program had started. Various scenarios were tested where different pricing schemes for free-floating carsharing were assumed. The analyses made on the simulation results were aimed at understanding how demand is influenced by free-floating pricing schemes, assuming that the characteristics of the existing traditional carsharing 
program are fixed. The hypothesis is that different pricing schemes will not only impact usage numbers, but new usage patterns will also emerge. Testing this hypothesis is the main goal of the study. The methodology proposed is not yet mature enough to represent market dynamics and competition, but looking at the impact of different pricing schemes is a step in this direction.

The remainder of this paper is organised in five sections. The next section provides the background of the research presented. In "Methodology" section, the methodology is described in more detail. "Simulation scenarios" section describes the scenarios used for the experiments. The results of the simulations are presented in "Simulation results and discussion" section, and their value and limitations are discussed. The "Discussion" section presents the conclusions and proposes venues for future work.

\section{Background}

Carsharing has a peculiar price structure. The fixed costs typical of car ownership are nearly all transformed into variable costs (Steininger et al. 1996). Car use is paid by the hour, or in the case of free-floating carsharing by the minute, and there is usually a membership fee, which in most cases is not substantial and sometimes is even refundable. Pricing is clearly one of the factors influencing modal choices. Various researchers (Simma and Axhausen 2003; Verhoeven 2010; Beige and Axhausen 2012) have argued that modal choices are influenced by long-term decisions of getting access to a portfolio of mobility tools. In this view, the daily choice of which mode to use, among those available, is interdependent with the long-term decisions. In the work of Le Vine et al. (2014), this concept has been explored assuming that the decision to use carsharing has both a strategic and a tactical level. It is assumed that at the strategic level, carsharing membership is weighed against other long-term decisions, like buying a car or buying a public transport season ticket. At the tactical level, carsharing is considered an alternative to other available modes. Following this idea of two decision levels, it appears that the relationship between carsharing pricing and modal choices has been explored mostly at the strategic level and almost exclusively in the broader discussion of carsharing potential. Several studies estimated carsharing potential for a given city or area. A technique popular among various researchers and applied in different versions, consists of assuming a certain yearly level of car use for given categories of individuals. Then the costs incurred travelling with a private car and with carsharing are calculated and compared. If the cost for carsharing is lower, the individual is counted as a potential car-sharing user. Here below some few examples of this technique are shortly reviewed.

Petersen (1995), found that in the German market, the break-even point in terms of annual kilometres travelled, i.e., the usage level at which the kilometric cost of carsharing and that of a private car are equal, was $18,000 \mathrm{~km}$ per year, or $15,000 \mathrm{~km}$ per year when insurance is taken into account. Based on this, Prettenthaler and Steininger (1999) found that, according to the Austrian average yearly mileage, $69 \%$ of Austrian households living in an urban area would have a financial benefit from joining carsharing. Schuster et al. (2005) estimated that about $4 \%$ of private vehicles in the Baltimore area (USA) could be substituted by carsharing. They came to this conclusion using revealed travel data of a representative sample of Baltimore's population. They then calculated yearly costs for all vehicles of the sample and compared ownership cost with sharing cost for all of them. 
One of the limitations of these studies is that they assumed a price for carsharing, in most cases the price of an existing carsharing program in the study area, and did not explore how the potential depends on the price level or price structure.

Looking at the tactical level, the literature is very limited. The paper of Breitner and Klein (2012) reports on work where they calculated a suitable price model for students at a university campus in Hannover, Germany. The goal of the study was to find a price that, given a certain willingness of the students to pay, would have maximised car-sharing use.

In general, it seems that the topic has been almost completely neglected by carsharing researchers. In the history of modern carsharing can be found a possible explanation for the lack of research on the topic. When modern carsharing operations started in Europe in the 1990s most car-sharing operators were working in conditions close to those of a 'local monopoly', and this situation lasted for years. Since cities with multiple car-sharing operators in Europe and North America were an exception, operators often did not have any direct competitors. In this sense, it is not surprising that pricing was not a popular research topic. One might argue that this is not completely true since operators did have to compete with other businesses providing similar services. Taxis and car rentals were probably the closest competitors. But the peculiar price structure of carsharing, and to some extent the ideological motivation of the users - especially in the early days of modern carsharingsuggests that round-trip carsharing was rather complementary to taxi and rental cars (Millard-Ball et al. 2005). In some Chinese cities, as documented in Wang et al. (2012), carsharing might indeed compete with taxis, but this might be an exception because of the comparatively large diffusion and low costs of taxis. Otherwise, the carsharing literature offers no evidence of any direct price competition between traditional carsharing and other modes.

From this short overview, it seems evident that there is a research gap regarding how car-sharing pricing affects demand. There is also the contingent situation of the carsharing industry directing research efforts toward more urgent topics. It was suggested in the previous section, that the emergence of free-floating carsharing will likely be a big factor in promoting more research in this area. At the strategic level, carsharing potential will not be the main issue anymore; rather the potential of each of the operators in the carsharing market will need to be determined according to pricing and to the services offered. Individuals might decide to become members of a particular car-sharing program over another one, or even of more than one. The pricing and the characteristics of the service, together with the users' specific needs for a particular trip chain, will then be the determining aspect of carsharing demand on a daily basis.

\section{Methodology}

To test the impact of different pricing schemes on carsharing demand, such schemes were implemented in a travel demand simulation: the multi-agent traffic simulation MATSim (MATSim 2014; Balmer et al. 2009). Agent-based modelling in transportation is still relatively new and is mainly related to activity-based demand generation and dynamic traffic assignment. Activity-based demand generation creates a list of activities connected with trips for each person in a study area. Examples like ALBATROSS (Arentze and Timmermans 2005; Beck et al. 2009), CEMDAP (Bhat et al. 2004) and TASHA (Roorda et al. 2008) follow this approach and indeed provide sophisticated models for activitychain generation at the individual level using agent-based modelling. Dynamic traffic 
assignment, a modelling approach that allows taking into account the interactions among the route choices that travellers make, and the congestion that results from their travel over the network.

DynaMIT (Ben-Akiva et al. 2002), Dynasmart (Mahmassani et al. 1992) and the dynamic version of Visum (Vrtic and Axhausen 2003) are focused on solving the dynamic traffic assignment problem using iterative processes. These models are not agent-based, but there is a belief that agent-based modelling is suitable for integrating activity-based demand generation with dynamic traffic assignment. In fact, a limited number of academic projects attempt to combine these two approaches. FEATHERS (Bellemans et al. 2010) was developed as an extension of ALBATROSS and has been used in many studies in the Flanders area in Belgium (Knapen et al. 2011; Dhondt et al. 2012).

TRANSIMS (Smith et al. 1995; Simon et al. 1999) is an agent-based model where the synthetic population used in the simulation is generated using household surveys. Each agent has his own daily activity pattern. The simulation predicts travel by finding an equilibrium state for the transportation system through an iterative process. The main limitation of this tool is the fact that agents can only adjust their route. MATSim has a similar approach, but several travel dimensions, i.e., time, activity location, mode, etc., can be adjusted by the agents during the simulation in order to improve their daily plans. The dynamic assignment is based on a physical simulation of traffic vehicles interacting in a simplified manner.

Agent-based approaches have already been used to model innovative transport modes. They are suitable in particular to simulate those modes where the exact location of individual vehicles is important for the modelling exercise. For example, this is the case for electric cars for range and recharging issues (Dhondt et al. 2012; Waraich and Axhausen 2012) and, for carsharing because of the importance of the availability at a given place at a given time (Ciari et al. 2013). MATSim, specifically, is suitable to model carsharing. It supports a very detailed and close to reality specification of the carsharing service, (i.e., cars geographical location, price structure, car availability) embedded in a realistic representation of a study area. The fact that trip chaining and activities are explicitly modelled in MATSim is also important because allows capturing activity chains which are best served by carsharing given its peculiar price structure.

\section{Available modes}

In MATSim, as a standard, four modes are simulated: (private) car, public transit, bicycle and walk. Additionally, the simulation was already used to model carsharing demand for both round-trip based carsharing (Ciari et al. 2012) and free-floating carsharing (Ciari et al. 2013). MATSim in its standard form does not simulate taxi travel. This relates to the limited availability of specific information, which is consequence of the very low modal share in the study area $(0.13 \%$, slightly above the national figure of $0.11 \%)$ and the unwillingness of the taxi industry to share information. For general purpose, this makes the simulation of taxis in the Swiss context extremely unattractive because it is both not very relevant and difficult to set up. However, for the present study, this was a limitation since, given the type of service provided, free-floating carsharing is a possible competitor of taxis. Taxi service was therefore added to the simulation. It was implemented as a car mode that is available in the simulation everywhere and can be used for single trips (other modes, i.e., car and bike are subtour based). The price for a taxi in the simulation is set to 3.8 SFr/km, which is consistent with current prices in Zurich. 


\section{Carsharing travel}

The use of round-trip carsharing by an agent in the simulation is modelled in the following steps:

1. Reserve the nearest available car.

2. Walk from start activity to the station where he reserved the car.

3. Get the car.

4. Drive to the next activity (interaction with other vehicles are modelled).

5. Park the car close to the next activity.

6. Take the car again and drive to the next activity.

7. From the last activity of the chain, drive to the initial station.

8. Drop the car.

9. End the rental (and make the car available for other rentals).

The use of free-floating carsharing by an agent is simulated using similar steps, but the rental ends with the end of one trip:

1. Rent the nearest car.

2. Walk from start activity to the rented car.

3. Drive to the next activity (interaction with other vehicles are modelled).

4. Park the car close to the next activity.

5. End the rental (and make the car available for other rentals).

\section{Carsharing membership}

Membership for the round-trip carsharing program in the simulation is assigned to the agents running a binary logistic regression model, which was estimated on a representative sample of the Swiss population. The estimation of the model itself has been documented in Ciari et al. (2015). The membership model takes into account both socio-demographic attributes of the agents and accessibility at the individual level. Accessibility is calculated at the micro level, i.e., the actual number of available cars within a given distance, as opposed to the macro level, if a carsharing program is active in the macro area of residence, for instance, the city. Total accessibility includes both accessibility from home and from work, and is calculated with the following formula:

$$
A(p)=\ln \left(\sum_{i=1}^{n} X_{i} \times e^{-\beta \times \text { dist }_{i h}}\right)+\ln \left(\sum_{\mathrm{j}=1}^{n} X_{\mathrm{j}} \times e^{-\beta \times d i s t_{\mathrm{j} w}}\right)
$$

The weight parameter $\beta$ is set to 0.2 as in Weis (2012); dist ${ }_{i h}$ and $d i s t_{j w}$, are calculated as the distance between station $i$ and home location and station $j$ and work location of person $p$ respectively; $X_{i}$ is the number of cars at station $i$ and $X_{j}$ is the number of cars at station $j$.

The first free-floating program in Switzerland started operations in Basel in August 2014 (Catch-a-Car, 2014). This is operated by Mobility (Mobility 2014) which runs also traditional round trip carsharing throughout Switzerland. Being free-floating just arrived in Switzerland, membership data is not yet available. In order to model free-floating carsharing membership in the simulation, members' socio-demographics of other programs, active in other countries, were thus the only possible reference. It was possible to obtain some data of DriveNow's membership for the city of Munich, Germany which was subsequently used to create a simple membership model. In that program, each car attracts 
slightly more than 100 members (100,000 members with 900 vehicles). In addition, $80 \%$ of the members are male and are distributed over the age groups as shown in Fig. 1.

Members were drawn from the population of agents and fitted to the above numbers. An overlapping between traditional carsharing membership and free-floating was also assumed. In accordance with the findings of Scherf et al. (2013) for Berlin, Germany, $30 \%$ of free-floating members are also round trip carsharing users.

\section{Evaluation of carsharing travel}

During the simulation, each agent tries to optimise its plan through trial and error (expressed by an iterative process). He can for example change his route, his means of transportation, the schedule of activities and the location of leisure and shopping activities. The utility of a plan (based on Charypar and Nagel, 2005) corresponds to the sum of the utility of the performed activities $U_{a c t, i}$ minus the disutility associated with travel (transportation cost) $U_{\text {trav }, i}$

$$
U_{\text {plan }}=\sum U_{a c t, i}\left(\text { type }_{i}, \text { startt }_{i}, \text { dur }_{i}\right)+\sum U_{\text {trav }, i}\left(\operatorname{loc}_{i-1}-\operatorname{loc}_{i}\right)
$$

Using type $e_{i}$ : the type of the performed activity; start $_{i}$, the start time of the activity and $d u r_{i}$ its duration,a score is assigned to each executed plan according to the utility the agent will get by carrying it out. The agent will try to keep the plans with the better scores and discard the worst ones during the process. In principle, activities are evaluated positively (provide utility) and travel evaluated negatively (generates negative utility). The specific components of carsharing travel are as follows:

- Time cost for walking (access + egress)

- Monetary cost of distance (a free distance can be set)

- Monetary cost of rental time (a maximum cost can be set)

- Constant for carsharing (minimum cost)

The components above can be set to the desired levels according to the carsharing program that the modeller wants to simulate. Through the scoring function, agents are able

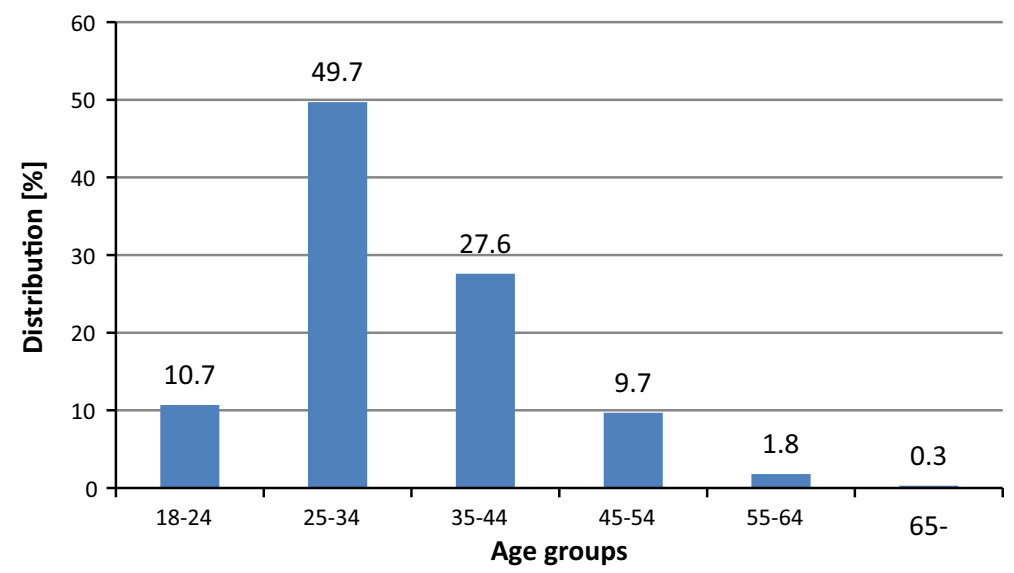

Fig. 1 Distribution over age groups of free-floating program members 
to evaluate different modal options. The agents evaluate the mobility options they have and through an iterative process driven by a genetic algorithm choose the one that fits their needs best. The availability of the other modal options is an attribute of the agent and is assigned based on its socio-demographic characteristics and reflects the actual distribution observable in census data.

\section{Pricing schemes}

Prices for round-trip and free-floating carsharing in the simulation are based on the current prices of Mobility and Catch-a-car. Various pricing schemes for free-floating carsharing were tested. No changes were hypothesised for round-trip carsharing pricing. This assumption can be justified by the fact that Mobility prices were not changed after the introduction of Catch-a-car in Basel. Additionally, it is now worth repeating that the main focus of the study is not to represent a competition process between two operators, but rather to show how changes in pricing can steer modifications in carsharing demand beyond total use numbers. The expected increased competitiveness in the carsharing market is an important motivation to test and further develop the methodology used. The pricing schemes hypothesised were created by keeping in mind that changes in price, as compared to the actual price, should be large enough to steer visible changes, but still remain plausible. There were two main reasons for not trying to use more sophisticated approaches to create them. The first is the difficulty encountered in getting precise information on operational costs. This information would be needed in order to apply such models. The second is the computation time of the simulation, about $50 \mathrm{~h}$ for the configuration used, which places a limit on the number of simulation runs involved in a study.

\section{Simulation scenarios}

As case study for the simulation, the metropolitan area of Zurich was chosen. The main reasons for this choice are (a) Zürich has a large round-trip carsharing supply, but no freefloating carsharing, (b) the existence of a well-tested MATSim scenario already used to model round-trip carsharing demand. The area covers about $2800 \mathrm{~km}^{2}$, obtained by drawing a $30 \mathrm{~km}$ circle around the 'Bellevue' square in the city centre. The agent population was generated using geo-coded data from the year 2010 population census (individuals, households, commuting matrices), the year 2008 census of workplaces (facilities by type and capacity) and the national travel survey for the year 2010 (Swiss travel diaries survey, ARE and BFS 2012). The 9731 types of activity chains were classified by the duration of the activities, their number, types and sequence; eight classes of agents by age and work status and the chains are assigned to them accordingly. The study area has approximately 1.7 million inhabitants. Moreover, the population contains all agents that have plans with at least one activity within the area and all agents crossing the area during their travel. The road network model is based on the Teleatlas navigation network and has more than 236,000 directed links and more than 73,000 nodes. For computational reasons, the simulation is run on a $25 \%$ sample of the population, which means that 445,304 agents are simulated. The network capacity is also scaled (each link's capacity is set to $25 \%$ of the original capacity) in order to have realistic traffic flows on the network links. The number of members for both carsharing types and the number of cars were also scaled accordingly. For round-trip carsharing, the number of members obtained by applying the 
membership model described previously is 35,716 , which is close to the actual number of members in the area: 34,896 . Scaling it down to $25 \%, 8929$ members are simulated. The number of free-floating carsharing members in the simulated area, obtained by assuming a similar socio-demographic profile of the users with those of DriveNow and a similar members/car ratio (1000 members per car), is 22,500 (already scaled down). The high number of members per car is consistent with early evidence that free-floating carsharing is able to attract more members per car than traditional carsharing (Firnkorn and Müller 2011).

\section{Scenarios}

One-way carsharing services have recently started to operate alongside better-established round-trip carsharing services in a number of cities (e.g. Amsterdam, Berlin, Paris, Washington DC), and operators now seek to expand into others. Policy-makers require evidence on which to assess the impacts; to address this issue an agent-based simulation framework is employed on a case study of Zurich, Switzerland. Zurich was chosen as it is where one of the longest continuously-operating round-trip carsharing services in the world (since 1987) is located. Although there are not yet concrete hints of the introduction of oneway carsharing in Zurich, this might come in the near future, in particular, if the pilot in Basel proves successful. How this will compete with the existing carsharing is clearly an interesting question. It is worth noting here that 'compete' is used in a broad sense. This includes, but it is not limited to, the case in which a new operator comes to town and starts a free-floating carsharing program. It can also be applied to the case in which the operator running the round-trip program plans to extend its supply to include free-floating carsharing. This is what happened in Basel starting in September this year. In this case, borrowing the term from retail science, we might observe 'cannibalism' of one carsharing on the other. In both cases, the price set for the new carsharing service will have an impact on the interaction with the existing carsharing operator. The scenarios described here are aimed at exploring this interaction by assuming different pricing schemes for free-floating carsharing.

\section{Scenario I-round-trip carsharing only}

The first scenario reproduces the current situation: only round-trip carsharing is available in this scenario and the location and number of vehicles reflect that of Mobility with 551 vehicles (after scaling) at 492 stations. The fee for round-trip carsharing is also inspired by that of Mobility and is taken as 2.80 SFr. per hour plus 0.60 SFr. per km. This scenario has been calibrated so that actual carsharing use in the area is accurately reproduced by the simulation. The scenario was also tested with several random seeds in order to make sure that the observed results, for this and for the other scenarios, were actually not significantly affected by simulation variability.

\section{Scenario II-round-trip + free-floating with normal pricing scheme}

The second scenario sketches the introduction of free-floating carsharing in the city and around it. The service area coincides with the study area. This is a rather large area for this kind of service. The reason for this assumption is the peculiar distribution of traditional carsharing over Swiss territory. Carsharing is not only available in larger urban centres, as 
happens in most countries, it is also in small cities and even in villages. It was therefore assumed that free-floating carsharing supply in Switzerland would also be shaped in a similar way. Actually, the case of Basel does not confirm this. Basel is a very rare case of a tri-national urban area (substantial parts of its suburbs are in Germany and France) and therefore the usual approach was not an option, at least for the pilot. Free-floating cars in the simulation are initially parked on the link closest to the round-trip stations. The time fee for free-floating is set at $0.37 \mathrm{SFr}$ per minute, no distance cost apply, reflecting the Catch-acar pricing scheme.

\section{Scenario III-round-trip + free-floating with half-price}

This scenario assumes a more aggressive commercial approach for free-floating carsharing. The time fee is half of the earlier one set for the whole day.

\section{Scenario IV-round-trip + free-floating with half-price 10 am to $4 \mathrm{pm}$}

This scenario assumes a price policy for free-floating that offers two different prices for peak-time and non-peak time. Non-peak rentals (10 am to $4 \mathrm{pm})$ have a reduced time fee (the half) trying to challenge traditional carsharing on its own ground (many carsharing trips are off-peak).

\section{Scenario $V$}

This scenario assumes a price policy that mirrors the one of Scenario IV. The half-price is offered between $4 \mathrm{pm}$ and 10 am so it includes peak hours, but also hours with very low, or even nonexistent, demand.

The characteristics of all simulated scenarios are summarised in Table 1.

\section{Simulation results and discussion}

As stated earlier, MATSim is based on an iterative process that eventually reaches an equilibrium point. The behaviour of the agents in the last iteration of the simulation is the output of the simulation. That behaviour is a plausible approximation of the behaviour of the real individuals in the real system under the conditions sketched in the scenarios. The scenarios used here were running for 200 iterations until the equilibrium point was reached.

Table 1 Rental fees for round-trip (RT) and free-floating (FF) carsharing for all scenarios

\begin{tabular}{|c|c|c|c|c|c|}
\hline & Scenario I & Scenario II & Scenario III & Scenario IV & Scenario V \\
\hline RT time fee & 2.80 SFr./h & 2.80 SFr./h & 2.80 SFr./h & 2.80 SFr./h & 2.80 SFr./h \\
\hline $\begin{array}{l}\text { RT distance } \\
\text { fee }\end{array}$ & 0.60 SFr./km & 0.60 SFr. $/ \mathrm{km}$ & 0.60 SFr. $/ \mathrm{km}$ & 0.60 SFr. $/ \mathrm{km}$ & 0.60 SFr. $/ \mathrm{km}$ \\
\hline FF time fee & - & $\begin{array}{l}0.37 \mathrm{SFr} . / \mathrm{min} \\
(22.2 \mathrm{SFr} . / \mathrm{h})\end{array}$ & $\begin{array}{l}0.185 \mathrm{SFr} . / \mathrm{min} \\
\quad(11.1 \mathrm{SFr} . / \mathrm{h})\end{array}$ & $\begin{array}{l}0.185 \mathrm{SFr} / \mathrm{min} \\
(10 \mathrm{am} \text { to } 4 \mathrm{pm}) \\
0.37 \mathrm{SFr} / \mathrm{min} \\
\text { (rest of day) }\end{array}$ & $\begin{array}{l}0.185 \mathrm{SFr} / \mathrm{min} \\
(4 \mathrm{pm} \text { to } 10 \mathrm{am}) \\
0.37 \mathrm{SFr} / \mathrm{min} \\
\text { (rest of day) }\end{array}$ \\
\hline
\end{tabular}


Using 16 cores on 2 Intel Xeon E5-2697v2 processors at $2.7 \mathrm{GHz}$ and with $40 \mathrm{~GB}$ of RAM clocked at $1866 \mathrm{MHz}$ the runtime was around $36 \mathrm{~h}$.

\section{Simulation results}

The use of the round-trip carsharing in the base scenario is shown in Fig. 2.

Round-trip carsharing is used mostly in the morning with two additional peaks observable in the early afternoon and evening. It has been shown in a previous work (Ciari et al. 2012) that this result is consistent overall, although not perfectly reproducing actual carsharing use in the area. The simulation slightly underestimates carsharing usage in the afternoon. This aspect is discussed more in detail in the mentioned paper (Ciari et al. 2012).

Figure 3 shows use over the day of both carsharing types in all scenarios. Various facts are worth mentioning. The addition of free-floating carsharing has an impact on round-trip carsharing, but in terms of rentals distribution over time, does not seem dramatic.

The most relevant impact in terms of distribution over the day, happens only between 10 am and 4 pm (scenario IV) when half-price fees are introduced. With this pricing scheme, there is no peak for round-trip carsharing in the morning. Free-floating carsharing, with any pricing scheme, has three fairly pronounced peaks. The central one is particularly strong for scenario IV, when the price is reduced between 10 am and $4 \mathrm{pm}$, which was expected.

Table 2 gives an overview of some key figures for the different scenarios. As the price of free-floating carsharing changes, the number of users follows the expected pattern.

The number of rentals has a minimum with normal pricing and a maximum when the time fee is reduced all day to half-price (in the other scenarios, half-price is offered only during a limited time window).

It is apparent that round-trip and free-floating carsharing are mainly used for different types of trips. Trips made with round-trip are, on average, longer both in terms of distance and time. Numbers change with different pricing schemes, but changes are not large and no

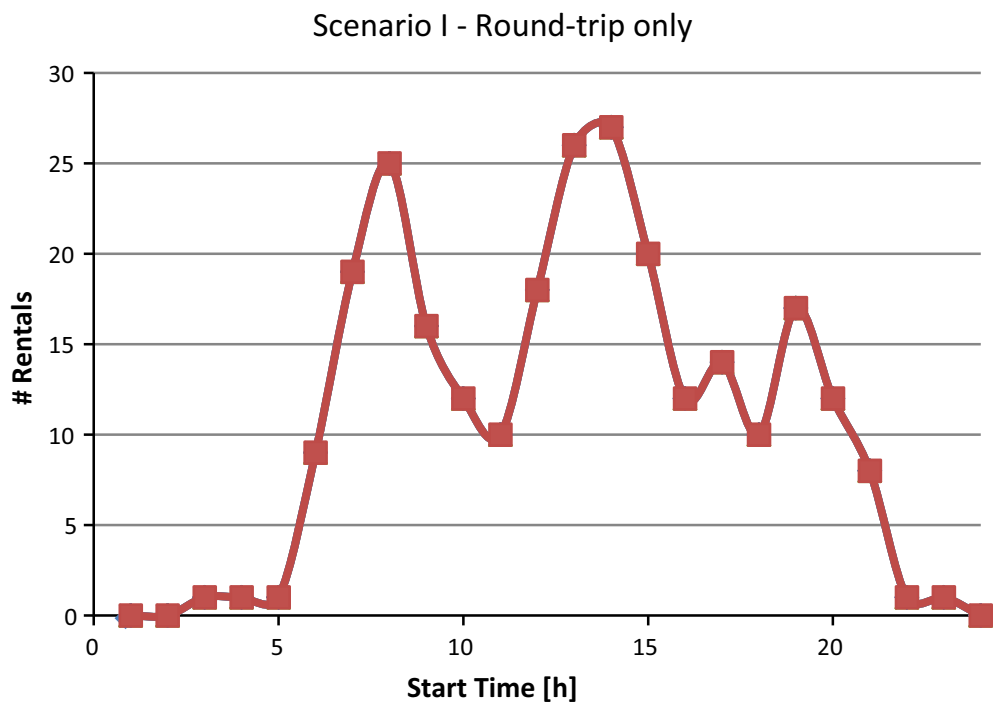

Fig. 2 Departures over the day in the base scenario 

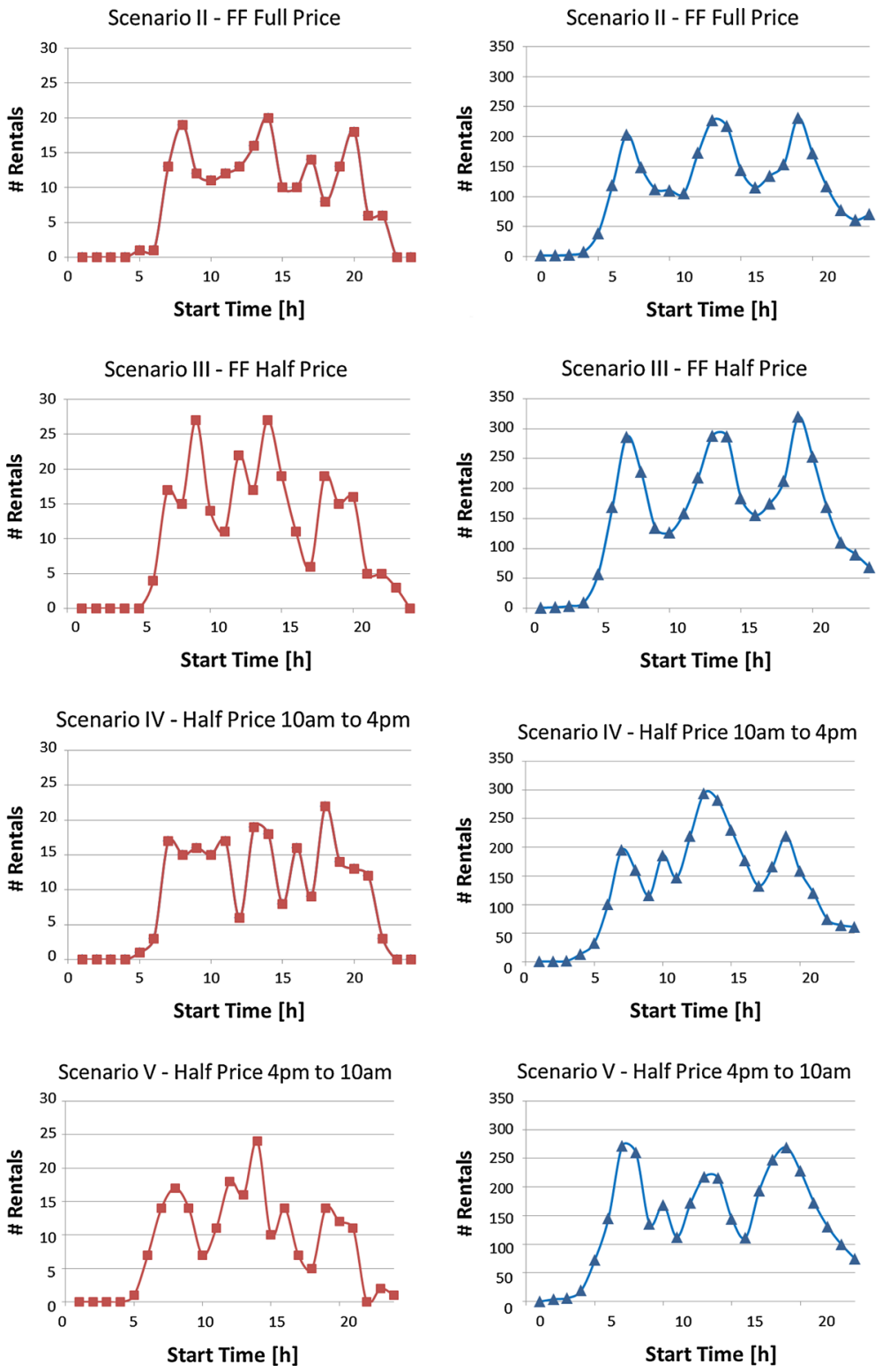

Fig. 3 Departures over the day in scenarios II to V

particular pattern is observed. An interesting pattern, however, is observable looking at the impact of the different pricing schemes on round-trip carsharing. Rentals have a maximum when free-floating is offered at half-price all day. This is not necessarily intuitive. This seems to support the idea that these two types of carsharing are rather complementary and not really competitors. There are a small number of agents that use both types of carsharing during the simulation in all scenarios. But these numbers, though not negligible, are not 
Table 2 Key figures of the simulation output for scenarios I to $\mathrm{V}$

\begin{tabular}{llllll}
\hline Variable & Scenario I & $\begin{array}{l}\text { Scenario II } \\
\text { full } \\
\text { price } 0-24\end{array}$ & $\begin{array}{l}\text { Scenario III } \\
\text { half-price } \\
0-24\end{array}$ & $\begin{array}{l}\text { Scenario IV } \\
\text { half-price } \\
10 \mathrm{am}-4 \mathrm{pm}\end{array}$ & $\begin{array}{l}\text { Scenario V } \\
\text { half-price } \\
4 \mathrm{pm}-10 \mathrm{am}\end{array}$ \\
\hline Unique users RT & 252 & 194 & 244 & 221 & 200 \\
Unique Users FF & - & 2374 & 3106 & 2646 & 2914 \\
Users both & - & 20 & 41 & 22 & 21 \\
Rentals RT & 261 & 203 & 253 & 224 & 205 \\
Trips RT & 659 & 470 & 665 & 542 & 495 \\
Rentals FF & - & 2821 & 3809 & 3234 & 3557 \\
Vehicles used RT & 216 & 171 & 206 & 186 & 180 \\
Vehicles used FF & - & 542 & 543 & 539 & 546 \\
Vehicles used (total) & 216 & 713 & 749 & 725 & 726 \\
Avg. rental time RT(s) & $13,460 \mathrm{~s}$ & $11,974 \mathrm{~s}$ & $13,569 \mathrm{~s}$ & $12,615 \mathrm{~s}$ & $13,046 \mathrm{~s}$ \\
Avg. rental time FF & - & $351 \mathrm{~s}$ & $415 \mathrm{~s}$ & $380 \mathrm{~s}$ & $426 \mathrm{~s}$ \\
Avg. rental dist. RT & $13.1 \mathrm{~km}$ & $11.7 \mathrm{~km}$ & $11.4 \mathrm{~km}$ & $11.5 \mathrm{~km}$ & $12.1 \mathrm{~km}$ \\
Avg. rental dist. FF & - & $4.5 \mathrm{~km}$ & $5.5 \mathrm{~km}$ & $4.9 \mathrm{~km}$ & $5.6 \mathrm{~km}$ \\
Avg. rentals per car RT & 1.24 & 1.19 & 1.23 & 1.20 & 1.14 \\
Avg. rentals per car FF & - & 5.20 & 7.01 & 6.00 & 6.51 \\
Turnover RT [SFr] & 4783 & 3315 & 4400 & 3742 & 3568 \\
Turnover FF [SFr] & - & 6076 & 4857 & 5798 & 5826 \\
Trips taxi & 1522 & 1429 & 1563 & 1490 & 1477 \\
\hline RT & & & &
\end{tabular}

$R T$ round-trip carsharing, $F F$ free-floating carsharing

large enough to explain the entire increase. Complementarity might exist at a different level. For example, free-floating can attract former round-trip users freeing up some capacity in the round-trip system. This can be used by other members who could not find an available car before.

The revenue for the various schemes has been also calculated. Actually, since no empirical data was available to impute the costs of operating the system, it is unclear how realistic the different pricing schemes were, in particular, those with the time fee reduced to half the regular price. One should be very cautious in the interpretation of the simulated revenue, which gives rather a general feeling on the different schemes. The highest revenue for free-floating carsharing in the simulation is obtained with full price (scenario II, which also has the lowest number of rentals), while the lowest is obtained when half-price is applied all day long - which also has the highest number of rentals. More interestingly, the two scenarios where half-price is offered in a specific time interval (IV and V), compared to the scenario with a full free-floating price, have more customers and only marginally lower revenue. These strategies seem therefore more successful than offering half-price all day. Additionally, if both systems are run by the same operator, these two schemes generate a higher total revenue then full price all day. It should be also noted that it is somewhat counter-intuitive that both scenarios IV and V generate revenues close to the full price all day scheme-and much higher than the half-price all day scheme. Indeed, this seems to hint at the fact that, from one simulation to the other (and from one scheme to the other), only a limited number of trips travelled by free-floating carsharing are exactly the 
same trips. Therefore, the changes in pricing seem to cause different agents to use carsharing. Table 3 further supports this idea.

Looking at any pair of scenarios where free-floating is available, only between 680 and 882 uses are the same (total users range from 2374 to 3106). Additionally, among the agents who used carsharing at least once; about $70 \%$ of them used it in only one or two of the simulations. This might seem a negative outcome for carsharing-customers are not loyal-but in fact, this is not necessarily the case. Changing the pricing means making carsharing more, or less, attractive, but it also creates a new pattern for the spatiotemporal availability of certain vehicles. An agent who used carsharing in, say, scenario II, might not use it in scenario III because of the different price. The vehicle is then available for somebody else who will likely use it in a different way (in terms of rental time and, for free-floating, drop-off location). This might imply another agent having the possibility to use this same car, which he did not have when the first agent was using it. This fact is obvious in a way, but the ability to capture it is an important feature of the agent-based simulation used in this work. A way to look at these changes in the demand, which are deeper than aggregate numbers would suggest, comes from a spatial representation of vehicles used in the simulation. The location of free-floating departures is shown in Fig. 4.

Comparing the scenarios, spatial patterns are similar, but also different. As a consequence of different pricing schemes, users are changing and rental locations are changing too. To have a numerical measure of this change, further corroborating what has been shown in the previous figure, the simulation area was subdivided into squares of two for two kilometres. If the price has no spatial effect, one should expect that across different scenarios the difference in terms of number of rentals within the squares should be close to a uniform distribution and reflect the difference in the aggregate. Figure 5, taking scenario III and IV as examples, shows that this is not the case.

The difference of free-floating use between the two scenarios is about $16 \%$, with scenario III having a larger aggregate usage. The graph shows that in most of the cases, the difference is not close to this level and there are also several cases where free-floating use is higher for scenario IV. The effect is similar between all scenario pairs.

A final analysis of the spatial effect is shown in Table 4 where the zones used for the previous analysis are grouped in three 'rings' (the central one broadly corresponding to central Zurich, the outer includes all of the most important suburbs).

Scenario III and IV are again taken as examples and the number of zones experiencing an increase, decrease, or absence of variation in free-floating rentals are reported for the three rings. Analogous to the previous analysis, an absence of spatial effects would be reflected by having all zones experiencing an increased number of rentals (since in scenario III there is a higher aggregate level of rentals). The values show that it does not happen since in all rings there are areas with unchanged and even with decreased number of rentals. The occurrence is especially evident in the two external rings. This hints, again, to

Table 3 Number of identical free-floating users for pairs of scenarios

\begin{tabular}{lllll}
\hline & Scenario II & Scenario III & Scenario IV & Scenario V \\
\hline Scenario II & $/$ & 814 & 705 & 680 \\
Scenario III & 814 & $/$ & 882 & 873 \\
Scenario IV & 705 & 882 & $/$ & 797 \\
Scenario V & 680 & 873 & 797 & $/$ \\
\hline
\end{tabular}



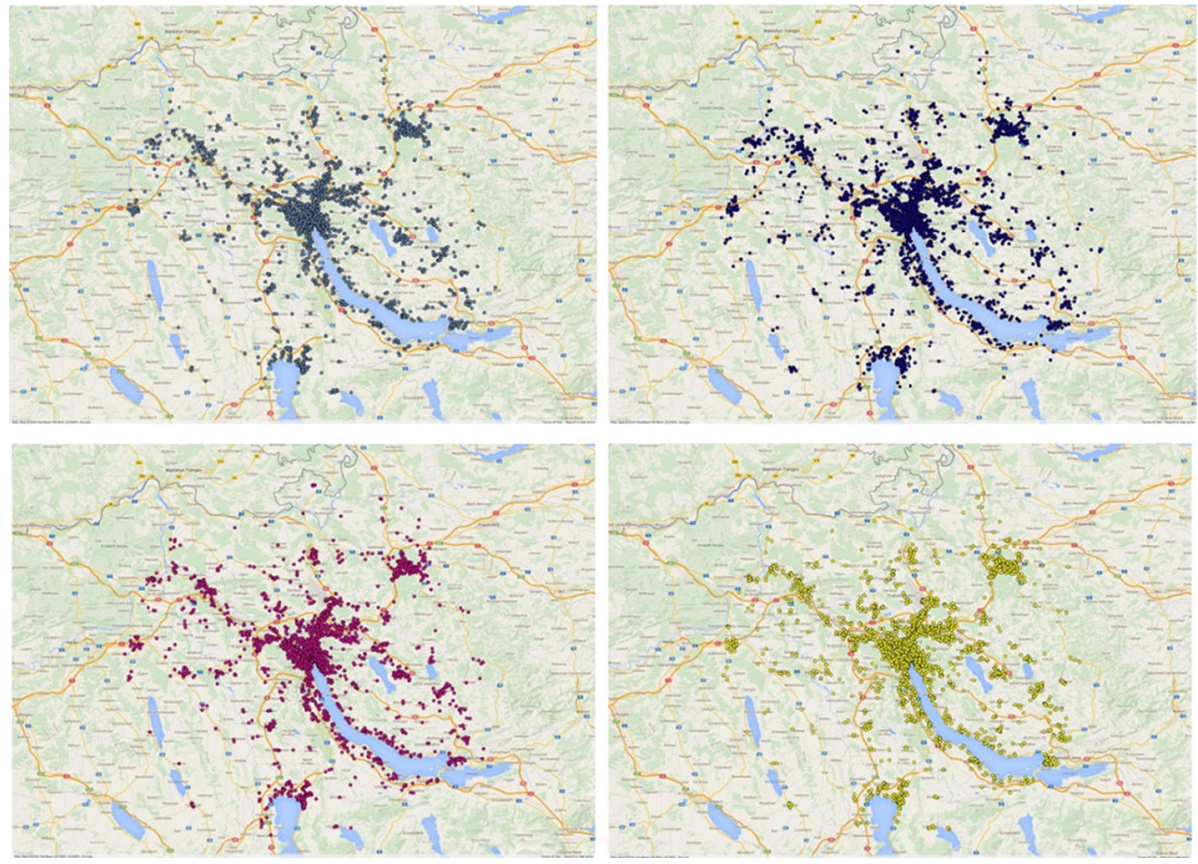

Fig. 4 Spatial distribution of free-floating carsharing trip departures, for scenarios II to V

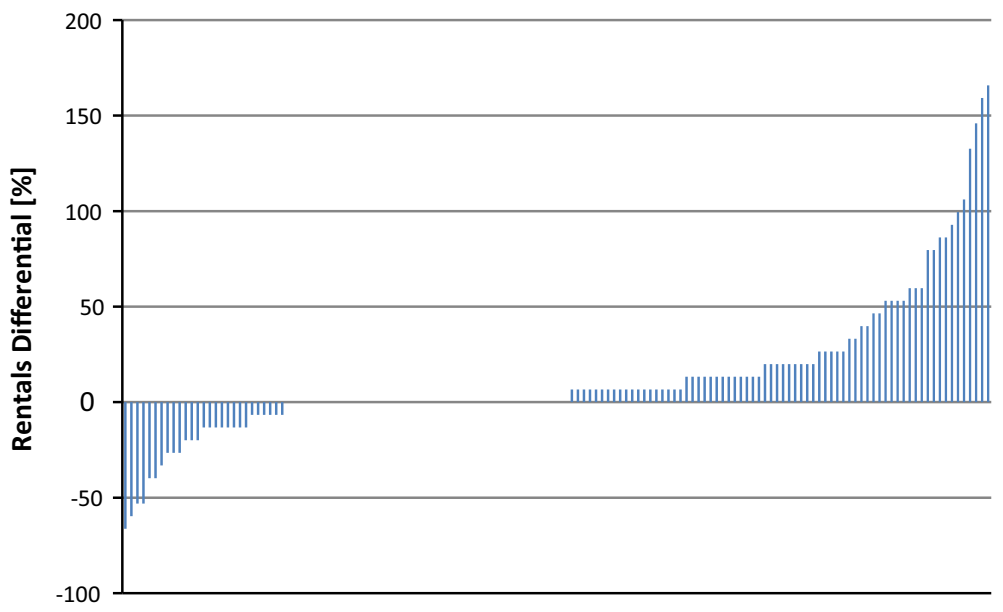

Fig. 5 Difference in number of rentals on predefined areas $(2 \times 2 \mathrm{~km})$ between scenario III and IV. Positive numbers correspond to more rentals in scenario III

a different localisation of free-floating carsharing usage driven by a change in the pricing scheme.

The next analysis sheds additional light on which modes are substituted by free-floating carsharing as compared to the base scenario (I). This is in Fig. 6. 
In the four scenarios where both carsharing types exist, only between 0.8 and $1.2 \%$ of freefloating trips were round-trip carsharing trips in the base scenario. Taxis are not really impacted by free-floating carsharing. Only about $0.1 \%$ of free-floating trips were taxi trips in the base scenario. Free-floating carsharing therefore captured only a handful of taxi trips. This is not to say that free-floating schemes do not compete with taxis in general, but rather that with a fleet of this size, the impact is negligible. Car is the mode most likely to be substituted by free-floating carsharing in all four scenarios. At least $40 \%$ of free-floating trips were car trips in the base scenario. However, a combined $50 \%$ of trips were either walking or public transport trips. This is not necessarily a good outcome if carsharing is supposed to have a positive environmental impact. However, it should not be forgotten that MATSim simulates only one average day and the possible long-term impact on travel behaviour are not captured. The outcome means, nevertheless, that substitution patterns should be checked closely when evaluating the impact of free-floating carsharing on the transportation system, in particular, from an environmental perspective. It is worthwhile noting here that substitution between the two types of carsharing depends on the assumed overlapping between their members. The one used here, as already mentioned, is supported by empirical evidence (Scherf et al. 2013). Experiments with different overlapping levels showed that this assumption does not particularly affect substitution patterns but do affect the magnitude of such substitution. A more comprehensive sensitivity study will be addressed in the future.

Another important dimension of travel is its purpose; this is reported in Fig. 7. For leisure and shop activities, round-trip carsharing is used more than free-floating. These results are quite consistent with expectations. However, as in a previous study (Ciari et al. 2012), the results would seem to challenge the common notion of carsharing as not being suitable for work activities.

Free-floating carsharing in the simulations is used in relation to a work activity in around $50 \%$ of the rentals. The figure for round-trip carsharing is about $10 \%$ lower. Studies based on empirical data (for example, Muheim 1998 and Cervero et al. 2007) found that work is the purpose of a carsharing rental in less than $10 \%$ of the cases. However, two additional aspects should be taken into account. One is looking at the temporal length of the working activity (Table 5).

Work activities related to free-floating carsharing are much longer than those related to round-trip carsharing, which is what one would expect given the service structure. Compared to activities reached by car, free-floating has even longer work activities. This makes sense if one thinks that car owners will eventually use a car for work independent of activity length. From this analysis, the idea that carsharing is not suitable for typical commuting (involving about $8 \mathrm{~h}$ of work) is definitely confirmed, or if one prefers, captured well by the simulation. Moreover, it should be noted that about $70 \%$ of the work activities related to carsharing usage in the simulations have work as the previous activity in the activity chain. For example, somebody going to work at one location and then going to another location to attend a workrelated meeting. This fits the concept of business carsharing — certain cars for a certain period

Table 4 Variation of free-floating carsharing rentals for the three rings, in parenthesis the number of zones where no rentals happened in any of the two scenarios

\begin{tabular}{lccc}
\hline & Central Zurich & Inner ring & Outer ring \\
\hline Decrease & 1 & 11 & 15 \\
Increase & 13 & 28 & 41 \\
Unchanged & 2 & $9(3)$ & $24(18)$ \\
\hline
\end{tabular}




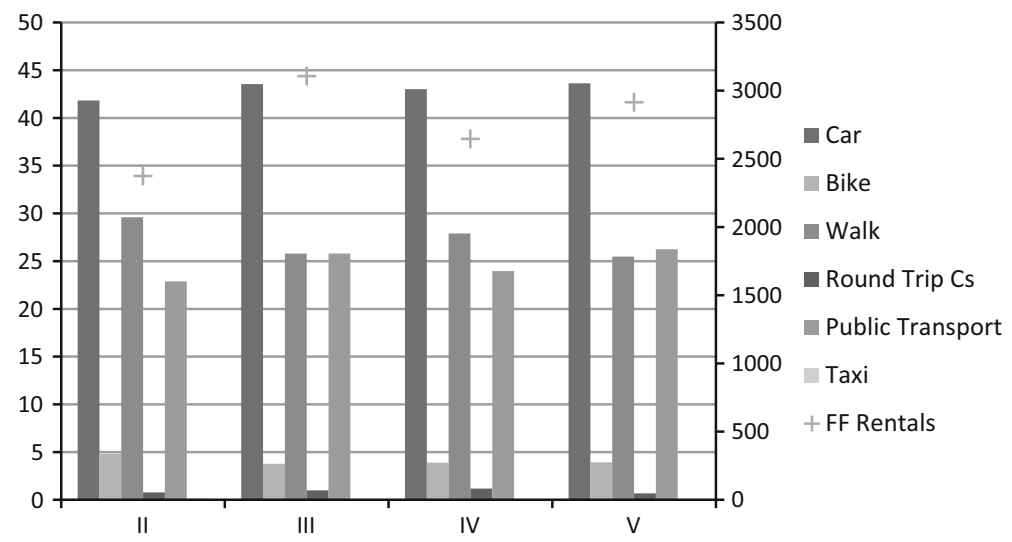

Fig. 6 Modes substituted by free-floating carsharing in scenarios II to V as compared to scenario I. The secondary axis shows the number of free-floating rentals for the scenario

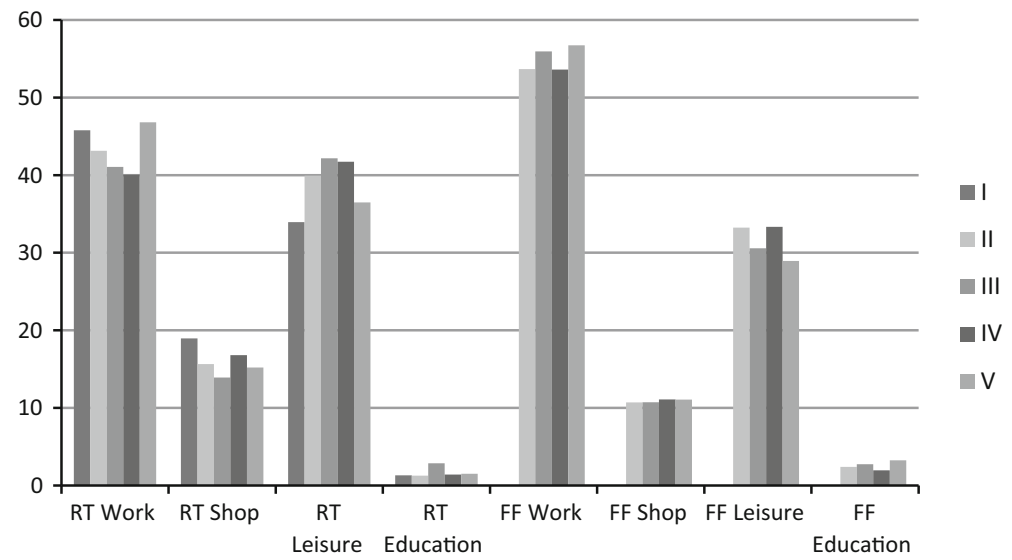

Fig. 7 Rental purpose for round-trip and free-floating carsharing for scenarios II to V

of time during the day are at the exclusive disposal of a firm's employees—which is actually offered by the Swiss operator Mobility and in 2005 accounted for about $20 \%$ of the total distance travelled by the Mobility fleet (Haefeli 2006). Business carsharing is not explicitly implemented in MATSim. The relatively high number of work-to-work trips in the simulations simply means that in the Swiss travel diaries surveys, which are reflected by agents' plans, there are chains involving such sequences and the simulation detects that they can be well served by carsharing.

\section{Discussion}

The results of this analysis suggest that pricing strategy structurally affects the interactions between the two carsharing types modelled in the study. A complex set of interactions are found between the spatiotemporal availability of carsharing vehicles on one side and its 
Table 5 Average temporal length of a work activity reached with a carsharing vehicle and with a private car

\begin{tabular}{llllll}
\hline & Scenario I & Scenario II & Scenario III & Scenario IV & Scenario V \\
\hline RT CS & $3 \mathrm{~h} 14^{\prime} 57^{\prime \prime}$ & $3 \mathrm{~h} 29^{\prime} 36^{\prime \prime}$ & $3 \mathrm{~h} 07^{\prime} 49^{\prime \prime}$ & $3 \mathrm{~h} 37^{\prime} 12^{\prime \prime}$ & $3 \mathrm{~h} 21^{\prime} 22^{\prime \prime}$ \\
FF CS & - & $6 \mathrm{~h} 21^{\prime} 10^{\prime \prime}$ & $6 \mathrm{~h} 40^{\prime} 43^{\prime \prime}$ & $6 \mathrm{~h} 09^{\prime} 14^{\prime \prime}$ & $6 \mathrm{~h} 52^{\prime} 02^{\prime \prime}$ \\
Car & $5 \mathrm{~h} 37^{\prime} 16^{\prime \prime}$ & $5 \mathrm{~h} 37^{\prime} 24^{\prime \prime}$ & $5 \mathrm{~h} 37^{\prime} 32^{\prime \prime}$ & $5 \mathrm{~h} 37^{\prime} 59^{\prime \prime}$ & $5 \mathrm{~h} 37^{\prime} 25^{\prime \prime}$ \\
\hline
\end{tabular}

users on the other. The impact of different pricing schemes is not limited to increasing or reducing the aggregate level of usage, but the analyses presented show that it also influences who is using carsharing, and where and when. To set up this kind of pricing experiment in a real-world setting would require substantial disruption to a carsharing operator's business, and therefore simulation is valuable for advance screening of operational strategies.

Several limitations of this study are noteworthy; they provide guidance for the future research agenda. First, the behavioural model of the agents does not take idiosyncratic personal tastes into account, for example, for transportation modes, i.e., in the form of individual-specific price elasticities. In principle, this analytical framework can accommodate such behaviour, but the relevant data would require a substantial effort to generate and was not available for this study. Further research is required to draw in more and wider coverage of pricing scenarios to enrich the understanding of consumer sensitivity to pricing strategies. The analysis reported here provides the first set of meaningful findings regarding the application of 'yield-management' pricing strategies by carsharing operators, but alternative carsharing business models can be expected to generate substantially different impacts. The study did not tackle the issue of the sensitivity of the results to several assumptions which were made. One notable example is that interactions between the two programs are much dependent on the level of overlap assumed between their members. This is a crucial point which will be necessary to address in order to answer concrete policy questions with this tool.

\section{Summary and outlook}

The work presented in this paper is motivated by the increasingly sophisticated operational practices in the carsharing industry. The increased size of the operators and the more frequent occurrence of direct competition are making carsharing pricing more salient than it has been until now.

One contribution of this work is methodological in nature; to the authors' best knowledge this is the first study to employ activity-based urban-scale simulation methods to forecast the impacts of temporally differentiated pricing strategies for carsharing. Carsharing in many cases requires negotiation between public and private actors; this research represents a step forward towards developing the predictive capacity required for sound decision-making in those negotiations.

A second contribution is to provide empirical results of how carsharing demand varies with different pricing strategies. This analysis suggests that the spatiotemporal profile of carsharing demand is likely to be sensitive to pricing structure. While this result is of 
interest to both carsharing operators and policymakers, in future better estimates will be made possible by generating stated-choice data regarding carsharing and integrating it into activity-based simulation methods.

At a strategic level, further development of the disaggregate (person-level and household-level) choice models underpinning urban-scale activity-based modelling techniques will enable more sophisticated treatment of individual people's behavioural responses. For example consumers have preferences for carsharing service features that have yet to be properly explored by researchers and have not been taken into account in this study (e.g. the desirability of having a 'guaranteed' reservation versus 'spontaneity'). Establishing such patterns of consumer preferences is an important direction for future research. Such modifications will improve the ability of the tool developed to deliver reliable system-level forecasts of the impact of new operational strategies.

\section{References}

Arentze, T.A., Timmermans, H.J.P.: Albatross 2: A Learning-Based Transportation Oriented Simulation System. European Institute of Retailing and Services Studies, Eindhoven (2005)

ARE and BfS: Mobilität in der Schweiz, Ergebnisse des Mikrozensus 2010 zum Verkehrsverhalten. Bundesamt für Raumentwicklung; BFS Statistik der Schweiz, Neuchâtel (2012)

Balmer, M., Axhausen, K.W.A., Horni, K., Meister, Charypar, D., Ciari, F.: Wirkungen der Westumfahrung Zürich: Eine Analyse mit einer Agenten-basierten Mikrosimulation, Final Report, Baudirektion Kanton Zurich, IVT, ETH Zurich, Zurich (2009)

Beck, C., Arentze, T.A., Int Panis, L., Janssens, D., Vankerkorn, J., Wets, G.: An integrated activity-based modelling framework to assess vehicle emissions: approach and application. Environ. Plan. B 36(6), 1086-1102 (2009)

Beige, S., Axhausen, K.W.: Interdependencies between turning points in life and long-term mobility decisions. Transportation 39(4), 857-872 (2012)

Bellemans, T., Kochan, B., Janssens, D., Wets, G., Arentze, T., Timmermans, H.: Implementation framework and development trajectory of FEATHERS activity-based simulation platform. Transp. Res. Rec. 2175, 111-119 (2010)

Ben-Akiva, M.E., Bierlaire, M., Koutsopoulos, H., Mishalani, R.: Real time simulation of traffic demand supply interactions with DynaMIT. In: Gendreau, M., Marcotte, P. (eds.) Transportation and Network Analysis: Current Trends, 19-36. Kluwer, Boston (2002)

Bhat, C.R., Guo, J.Y., Srinivasan, S., Sivakumar, A.: A comprehensive econometric microsimulator for daily activity-travel patterns. Transp. Res. Rec. 1894, 57-66 (2004)

Breitner, M., Klein, J.: In: S. Helber et al. (eds.), Operations Research Proceedings 2012, Springer International, pp 357-362 (2012)

Briggs, M.: FrostandSullivan. www.slideshare.net/FrostandSullivan/corporate-carsharing-3-1814 (2014). Accessed Sept 2014

Car2go. Car2go. www.car2go.com (2014). Accessed Jan 2014

Carsharing Berlin. Carsharing Berlin. www.carsharing-berlin.de (2014). Accessed Feb 2014

Catch-a-Car. Catch-a-Car. www.catch-a-car.ch/ (2014). Accessed Aug 2014

Cervero, R., Golub, A., Nee, B.: City CarShare: longer-term travel demand and car ownership impacts. Transp. Res. Rec. 1992, 70-80 (2007)

Charypar, D., Nagel, K.: Generating complete all-day activity plans with genetic algorithms. Transportation 32(4), 369-397 (2005)

Ciari, F., Schuessler, N., Axhausen, K.W.: Estimation of carsharing demand using an activity-based microsimulation approach: model discussion and some results. Int. J. Sustain. Transp. 7(1), 70-84 (2012)

Ciari, F., Bock, B., Balmer, M.: Modeling station-based and free-floating carsharing demand: a test case study for Berlin, Germany. Paper presented at the $93^{\text {rd }}$ Annual Meeting of the Transportation Research Board, Washington, D.C., January 2014 (2013)

Ciari, F., Weis, C., Balac, M.: Evaluating the influence of carsharing stations' location on potential membership: a Swiss case study. EURO J. Transp. Logist. (2015). doi:10.1007/s13676-015-0076-6 
Dhondt, S., Beckx, C., Degraeuwe, B., Lefebvre, W., Kochan, B., Bellemans, T., Int Panis, L., Macharis, C., Putman, K.: Health impact assessment of air pollution using a dynamic exposure profile: implications for exposure and health impact estimates. Environ. Impact Assess. Rev. 36, 42-51 (2012)

DriveNow. 30`000 Mitglieder in Berlin, press Communication, DriveNow (2012)

Firnkorn, J., Müller, M.: What will be the environmental effects of new free-floating car-sharing systems? The case of car2go in Ulm. Ecol. Econ. 70(8), 1519-1528 (2011)

Haefeli, U.: Evaluation of Carsharing. Bundesamt für Energie BFE, Bern (2006)

Knapen, L., Kochan, B., Bellemans, T., Janssens, D., Wets, G.: Activity based models for countrywide electric vehicle power demand calculation. In: Proceeding of IEEE SGMS'11, pp. 13-18 (2011)

Le Vine, S., Lee-Gosselin, M., Sivakumar, A., Polak, J.: A new approach to predict the market and impacts of round-trip and point-to-point carsharing systems: case study of London. Transp. Res. Part D 32, 218-229 (2014)

Mahmassani, H.S., Hu, T., Jayakrishnan, R.: Dynamic traffic assignment and simulation for advanced network informatics. In: Gartner, N.H., Improta, G. (eds.) Compendium of the Second International Seminar on Urban Traffic Networks (1992)

MATSim. MATSim. www.matsim.org (2014). Accessed Jan 2014

Millard-Ball, A., Murray, G., ter Schure, J., Fox, C., Burkhardt, J.: Car-sharing: where and how it succeeds, TCRP Report, 108, TRB, Washington D.C (2005)

Mobility Carsharing. Mobility. www.mobility.ch (2014). Accessed Aug 2014

Muheim, P.: Carsharing: The Key to Combined Mobility, Energy 2000. BFE Swiss Federal Office of Energy, Bern (1998)

Petersen, M.: Ökonomische Analyse des Car-Sharing. Gabler Verlag, Wiesbaden (1995)

Prettenthaler, F.E., Steininger, K.W.: From ownership to service use lifestyle: the potential of carsharing. Ecol. Econ. 28(3), 443-453 (1999)

Roorda, M.J., Miller, E.J., Habib, K.M.N.: Validation of TASHA: a 24-h activity scheduling microsimulation model. Transp. Res. Part A 42(2), 360-375 (2008)

Scherf, C., Steiner, J., Wolter, F.: E-Carsharing: erfahrungen. Nutzerakzeptanz und Kundenwuensche, Internationales Verkehrswesen 65(1), 42-44 (2013)

Schuster, T.D., Byrne, J., Corbette, J., Schreuder, Y.: Assessing the potential of carsharing: a new method and its implications. Transp. Res. Rec. 1927, 174-181 (2005)

Simon, P.M., Esser, J., Nagel, K.: Simple queuing model applied to the city of Portland. Int. J. Mod. Phys. C 10(5), 941-960 (1999)

Simma, A., Axhausen, K.W.: Commitments and modal usage: analysis of German and Dutch panels. Transp. Res. Rec. 1854, 22-31 (2003)

Smith, L., Beckman, R., Anson, D., Nagel, K., Williams, M.E.: TRANSIMS: transportation analysis and simulation system. Paper presented at the Fifth National Conference on Transportation Planning Methods Applications, Seattle, April 1995

Shaheen, S., Cohen, A.: Carsharing and personal vehicle services: worldwide market developments and emerging trends. Int. J. Sustain. Transp. 7(1), 5-34 (2013)

Steininger, K., Vogl, C., Zettl, R.: Car-sharing organizations: the size of the market segment and revealed change in mobility behavior. Transp. Policy 3(4), 177-185 (1996)

Verhoeven, M.: Modelling life trajectories and transport mode choice using Bayesian belief networks. Dissertation, Faculteit Bouwkunde, Technische Universiteit Eindhoven (2010)

Vrtic, M., Axhausen, K.W.: Experiment mit einem dynamischen Umlegungsverfahren. Straßenverkehrstechnik 47(3), 121-126 (2003)

Wang, M., Martin, E.W., Shaheen, S.A.: Carsharing in Shanghai, China: analysis of behavioral response to local survey and potential competition. Transp. Res. Rec. 2319, 86-95 (2012)

Waraich, R.A., Axhausen, K.W.: Agent-based parking choice model. Transp. Res. Rec. 2319, 39-46 (2012)

Weis, C.: Activity oriented modelling of short- and long-term dynamics of travel behaviour. Dissertation, IVT, ETH Zürich, Zürich (2012)

Francesco Ciari is Research Associate at the Institute for Transport Planning and Systems of the Swiss Federal Institute of Technology Zurich (ETH). His research interest is in shared-use vehicles and sustainable transportation. He also has several years of experience in agent-based travel demand modeling which he is currently teaching at ETH.

Milos Balac is a Ph.D. student at the Institute for Transport Planning and Systems at the ETH, Zurich. His work mainly focuses on modeling and optimization of carsharing systems, and estimation of the potentials of carsharing. 
Michael Balmer is Co-Founder and CEO of Senozon AG, an international consulting and technology company with specialization in location planning and site assessment, transport planning and transport systems. He has over 10 years of experience in agent-based travel demand modeling and software implementation, managing transport-related projects and he is committee member of the MATSim open source project. 